\title{
Herpes Zoster Cerebral Vasculopathy in a Case of Cognitive Decline
}

\author{
LM Dennis ${ }^{1}$, K Badger ${ }^{2}$ and R Mizoguchi ${ }^{3 *}$ \\ ${ }^{1}$ Department for Health and Aging, Guys and St Thomas' Hospital, London \\ ${ }^{2}$ Emergency Medicine, St Mary's Hospital, London \\ ${ }^{3}$ Care of the Elderly Department, Chelsea and Westminster Hospital, London
}

*Corresponding author: R Mizoguchi, Chelsea and Westminster Hospital NHS Foundation Trust, London

\section{ARTICLE INFO}

Received: 慧 July 18, 2019

Published:

Citation: LM Dennis, K Badger, R Mizoguchi. Herpes Zoster Cerebral Vasculopathy in a Case of Cognitive Decline. Biomed J Sci \& Tech Res 20(1)-2019. BJSTR. MS.ID.003390.

Keywords: Varicella Zoster Virus; Herpes Zoster; Vasculopathy; Cognitive Impairment; Dementia

\section{ABSTRACT}

Herpes Zoster vasculopathy is a recognised complication following reactivation of Varicella Virus however the long-term impact on cognitive function is not well known. An 83 years old woman presented with acute onset delirium, expressive dysphagia and vesicular rash in the ophthalmic distribution of trigeminal nerve due to Herpes Zoster Opthalmicus Infection (HZO). There was no focal neurological deficit. Laboratory results indicated an inflammatory response. CT Head (Figure 1) and CT Angiogram (Figure 2) showed temporal haemorrhagic stroke with widespread arterial stenosis suggestive of cerebral vasculitis. The patient was treated with intravenous acyclovir and methylprednisolone. Despite treatment, there was persistent cognitive impairment. It is important to consider Varicella Zoster infection as a potential cause of cognitive decline in the older population group. The presentation can be difficult to identify as patients may not always present with a vesicular rash. Therefore, early detection should be sought to initiate prompt treatment in elderly patients.

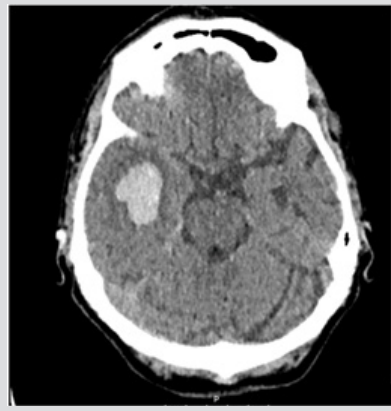

Figure 1: Acute intra-parenchymal haemorrhage right temporal lobe with evidence of modest perilesional oedema.

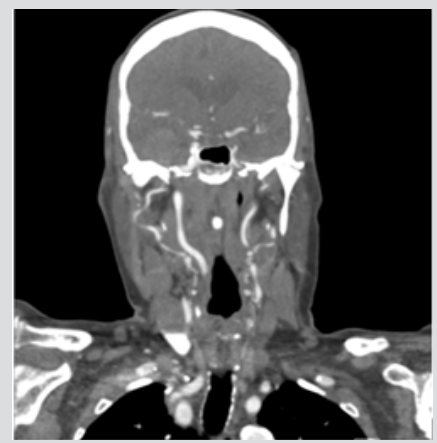

Figure 2: CT Angiogram showing widespread vessel narrowing suggestive of possible cerebral vasculitis. 


\section{Case Report}

An 83-year-old woman previously treated with oral acyclovir for Herpes Zoster Viral infection (HZV) presented with expressive dysphasia. There was a 3-week history of worsening confusion and an evolving vesicular rash in dermatomal distribution of ophthalmic branch of trigeminal nerve. Aside from a positive Hutchinson's sign, she had an unremarkable neurological examination. Laboratory testing showed raised inflammatory markers. CT Head revealed an acuteright temporal lobehaemorrhage. CT angiogram demonstrated widespread vessel narrowing suggestive of a possible cerebral vasculitis. A subsequent DWI MRI Brain was performed which showed an initial intracranial haemorrhage without any extension or interval bleed. A diagnosis of haemorrhagic stroke secondary to Varicella Zoster vasculitis was made and the patient was treated with high dose intravenous acyclovir and methylprednisolone. Cerebral Spinal Fluid (CSF) analysis showed 90\% mononuclear cells, polymerase chain reaction (PCR) was positive for Varicella Zoster Virus (HZV) DNA. Bacterial culture and vasculitic screen were negative. Despite intensive treatment, the patient revealed an on-going cognitive impairment which was reflected in her neuropsychometric assessment.

\section{Discussion}

Varicella Zoster Virus (VZV) is a human DNA alpha-herpesvirus. Initial exposure causes varicella infection. In elderly patients, cell mediated immunity declines. The virus remains latent lifelong in cranial nerve and dorsal root ganglia which can be associated with cranial nerve neuropathy upon reactivation as Herpes Zoster Infection (HZV) [1]. A significant complication of HZV infection is cerebral artery vasculopathy, which most commonly affects the ophthalmic distribution of the trigeminal nerve. The proposed mechanism of action is infection and remodeling of both large and small cerebral arteries via transaxonal spread, which can occur weeks to months following initial viral reactivation [2].

There is an increase in the risk of stroke has been shown to be associated with HZV infection when the ophthalmic distribution of the trigeminal nerve (HZO) has been affected [3]. This risk for both ischaemic and haemorrhagic stroke is seen to be most significant within in the first to three months following initial HZO infection, up to 4.5-fold in one population study when compared to matched cohort controls [4]. Although association between VZV and stroke is recognised, the impact on cognitive decline following infection is not well known. There is growing evidence that Herpes simplex Virus (HSV) may be a risk factor for dementia [5]. HSV in neuronal and glial cells can cause hyperphosphorylation of tau and increment of beta amyloid which is also seen in Alzheimer's Disease [6].

A large retrospective cohort study found that at 5 year follow up there was an increased risk of developing dementia following
HZO infection versus age-matched controls with relative risk ratio 2.82-2.97 ( $\mathrm{p}<0.001$ ) [7]. A population-based cohort study in Taiwan revealed there was a slightly increased risk of developing dementia (HR 1.11) following HSV infection. There was also a significantly reduced risk (adjusted HR 0.55) of developing dementia in those who had received treatment with Antiviral Therapy (AVT) after a mean follow period of 6 years [8]. Patients with HZV infection treated with AVT can have a significant reduction in risk of development of dementia by over $80 \%$ up versus non-treated controls and those who had received treatment $>30$ days were at lower risk of developing dementia [9-10].

These recent studies and as demonstrated in this case suggest there may be a causal link between HSV infection and risk of development of cognitive decline. There may also be a protective role of AVT against progression of developing dementia in longer term. It is important therefore to consider HSV reactivation particularly with ophthalmic nerve involvement in susceptible elderly patients as some clinical signs might not manifest at initial presentation. Early diagnosis is key to enable treatment with AVTs would increase the likelihood of a more favourable prognosis.

\section{References}

1. Arvin AM (1996) Varicella-zoster virus. Clinical microbiology reviews 9(3): 361-381.

2. Nagel M, Cohrs R, Mahalingam R, Wellish M, Forghani B, et al. (2008) The varicella zoster virus vasculopathies: Clinical, CSF, imaging and virologic features. Neurology 70(11): 853-860.

3. Lian Y, Zhu Y, Tang F, Yang B, Duan, R (2017) Herpes zoster and the risk of ischemic and hemorrhagic stroke: A systematic review and metaanalysis. PloS one 12(2): 0171182

4. Herng Ching Lin, Ching Wen Chien, Jau Der Ho (2010) Herpes zoster ophthalmicus and the risk of stroke: a population-based follow-up study. Neurology 74(10): 792-797.

5. Wozniak MA, Mee AP, Itzhaki RF (2009) Herpes simplex virus type 1 DNA is located within Alzheimer's disease amyloid plaques. J Pathol. 217(1): 131-138

6. Itzhaki RF (2017) Herpes simplex virus type 1 and Alzheimer's disease: possible mechanisms and signposts. The FASEB Journal 31(8): 32163226.

7. Tsai MC, Cheng WL, Sheu JJ, Huang CC, Shia BC, et al. (2017) Increased risk of dementia following herpes zoster ophthalmicus. PLoS One 12(11): e0188490.

8. Chen VC, Wu SI, Huang KY, Yang, YH, Kuo TY, et al. (2018) Herpes Zoster and Dementia A Nationwide Population Based Cohort Study. J Clinical Psychiatry 79 (1): 16m11312.

9. Tzeng NS, Chung CH, Lin FH, Chiang CP, Yeh CB, et al. (2018) Anti-herpetic Medications and Reduced Risk of Dementia in Patients with Herpes Simplex Virus Infections-a Nationwide, Population-Based Cohort Study in Taiwan. Neurotherapeutics 15(2): 417-429.

10. Itzhaki RF (2018) Corroboration of a Major Role for Herpes Simplex Virus Type 1 in Alzheimer's Disease. Frontiers in aging neuroscience 10: 324. 


\section{ISSN: 2574-1241}

DOI: 10.26717/BJSTR.2019.20.003390

R Mizoguchi. Biomed J Sci \& Tech Res

cC) (P) This work is licensed under Creative

Submission Link: https://biomedres.us/submit-manuscript.php

$\begin{array}{ll}\text { BIOMEDICAL } & \text { Assets of Publishing with us } \\ \text { RESEARCHES } & \text { - Global archiving of articles } \\ & \text { - Immediate, unrestricted online access } \\ & \text { - Rigorous Peer Review Process } \\ \end{array}$

